\title{
How to Determine the Environmental Exposure of PAHs Originating from Biochar
}

Mayer, Philipp; Hilber, Isabel; Gouliarmou, Varvara; Hale, Sarah E.; Cornelissen, Gerard; Bucheli, Thomas D.

Published in:

Environmental Science and Technology

Link to article, DOI:

10.1021/acs.est.5b05603

Publication date:

2016

Document Version

Publisher's PDF, also known as Version of record

Link back to DTU Orbit

Citation (APA):

Mayer, P., Hilber, I., Gouliarmou, V., Hale, S. E., Cornelissen, G., \& Bucheli, T. D. (2016). How to Determine the Environmental Exposure of PAHs Originating from Biochar. Environmental Science and Technology, 50(4), 1941-1948. https://doi.org/10.1021/acs.est.5b05603

\section{General rights}

Copyright and moral rights for the publications made accessible in the public portal are retained by the authors and/or other copyright owners and it is a condition of accessing publications that users recognise and abide by the legal requirements associated with these rights.

- Users may download and print one copy of any publication from the public portal for the purpose of private study or research.

- You may not further distribute the material or use it for any profit-making activity or commercial gain

- You may freely distribute the URL identifying the publication in the public portal 


\section{How to Determine the Environmental Exposure of PAHs Originating from Biochar}

Philipp Mayer, ${ }^{* \dagger}{ }^{\dagger}$ Isabel Hilber, ${ }^{\ddagger}$ Varvara Gouliarmou, ${ }^{\S}$ Sarah E. Hale," Gerard Cornelissen, ${ }^{\|, \perp, \#}$ and Thomas D. Bucheli ${ }^{\ddagger}$

${ }^{\dagger}$ Department of Environmental Engineering, DTU Environment, Technical University of Denmark, Miljøvej Bld. 113, DK-2800 Kgs. Lyngby, Denmark

${ }^{\ddagger}$ Agroscope ISS, Reckenholzstrasse 191, CH-8046 Zurich, Switzerland

${ }^{\S}$ Department of Environmental Science, Aarhus University, Frederiksborgvej 399, DK-4000 Roskilde, Denmark

"Department of Environmental Engineering, Norwegian Geotechnical Institute NGI, P.O. Box 3930 Ullevål Stadion, N-0806, Oslo, Norway

${ }^{\perp}$ Department of Environmental Sciences (IMV), Norwegian University of Life Sciences (NMBU), P.O. Box 5003, NO-1432 Ås, Norway

\#Department of Applied Environmental Sciences (ITM), Stockholm University, 10691 Stockholm, Sweden

\section{Supporting Information}

ABSTRACT: Biochars are obtained by pyrolyzing biomass materials and are increasingly used within the agricultural sector. Owing to the production process, biochars can contain polycyclic aromatic hydrocarbons (PAHs) in the high mg/ $\mathrm{kg}$ range, which makes the determination of the environmental exposure of PAHs originating from biochars relevant. However, $\mathrm{PAH}$ sorption to biochar is characterized by very high $\left(10^{4}-10^{6} \mathrm{~L} / \mathrm{kg}\right)$ or extreme distribution coefficients $\left(K_{\mathrm{D}}\right)\left(>10^{6} \mathrm{~L} / \mathrm{kg}\right)$, which makes the determination of exposure scientifically and technically challenging. Cyclodextrin extractions, sorptive bioaccessibility extractions, Tenax extractions, contaminant traps, and equilibrium sampling were assessed and selected methods used for the determination of bioavailability parameters for PAHs in two model biochars. Results showed that: (1) the $K_{\mathrm{D}}$ values of typically $10^{6}-10^{9} \mathrm{~L} / \mathrm{kg}$ made the biochars often act as sinks, rather than sources, of PAHs. (2) Equilibrium sampling yielded freely dissolved

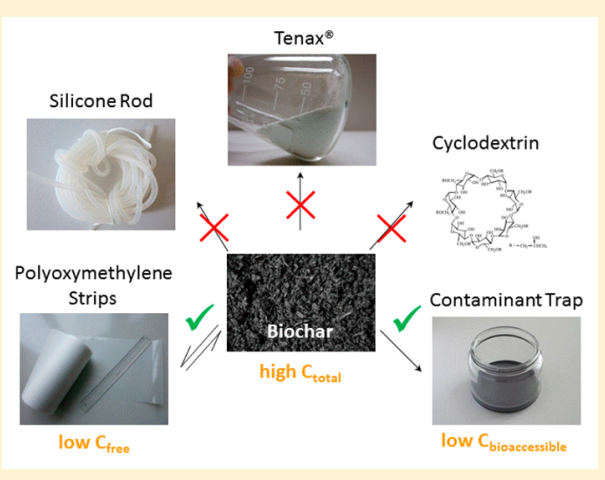
concentrations (pg-ng/L range) that were below or near environmental background levels. (3) None of the methods were found to be suitable for the direct measurement of the readily desorbing fractions of PAHs (i.e., bioacessibility) in the two biochars. (4) The contaminant-trap method yielded desorption-resistant PAH fractions of typically 90-100\%, implying bioaccessibility in the high $\mu \mathrm{g} / \mathrm{kg}$ to low $\mathrm{mg} / \mathrm{kg}$ range.

\section{INTRODUCTION}

Biochar is defined as "charcoal for application to soil" ${ }^{1}$ and has received much attention in the context of carbon sequestration, ${ }^{2,3}$ climate change mitigation, ${ }^{3}$ and soil improvement. ${ }^{3-12}$ Biochar is also used as an animal-feed supplement and conditioner to improve hygiene in stables ${ }^{13}$ and to conserve nitrogen in manure. ${ }^{14}$ Biochars are obtained from the pyrolysis of biomass and can thus contain considerable concentrations of coproduced polycyclic aromatic hydrocarbons (PAHs), which have been reported to be in the order of 1 to $100 \mathrm{mg} / \mathrm{kg}$ for the sum $(\Sigma)$ of the 16 U.S. Environmental Protection Agency(USEPA) defined PAHs. ${ }^{15,16}$ Previous studies have focused on total PAH concentrations in biochar, ${ }^{17-19}$ whereas the actual $\mathrm{PAH}$ exposure originating from biochar has received less attention. ${ }^{15,16}$ Soil-living organisms, plants rooted in soils, and some types of husbandry animals can be in close contact with biochar particles that have been amended to soils and contain elevated levels of PAHs. Suitable concepts and methods for assessing the environmental exposure of PAHs originating from biochars are thus required to carry out an adequate exposure assessment and when considering possible risk management strategies.

Biochars are carbon-rich materials of pyrogenic origin similar to other charcoals, activated carbon, and soot. All of these materials strongly sorb PAHs and are thus characterized by very high sorption coefficients $\left(K_{\mathrm{D}}\right)$ for these PAHs. ${ }^{20,21}$ It is this strong sorption that largely governs the fate and exposure of PAHs that are bound to particles of such materials. ${ }^{22,23}$ On the one hand, this strong sorption can be responsible for the very high PAH levels contained in many pyrogenic particles. On the other hand, for those PAHs that are already present in the

Received: November 13, 2015

Revised: January 15, 2016

Accepted: January 18, 2016

Published: January 18, 2016 
environment, strong sorption will often be an exposure reducing mechanism. ${ }^{24-26}$ Strong sorption of PAHs and other organic compounds to activated carbon has been utilized on an enormous scale in numerous exposure reduction technologies, including air purification, many forms of water treatment, food processing, and even medical applications. More recently, activated carbon has been amended to polluted sediments and soils to reduce contaminant exposure and mobility. ${ }^{20,27,28}$ The position of biochars between these two extremes of PAH source and PAH sink is at present less clear and therefore leads to the crucial question of whether PAHs coformed with biochar during pyrolysis give rise to significant environmental exposure.

Strong sorption to the biochar matrix makes the issue of limited bioavailability and limited exposure particularly relevant and their experimental determination particularly difficult. Conceptually, it is necessary to consider at least two complementary sides of bioavailability: ${ }^{29}$ (1) The chemical activity quantifies the potential for diffusion, sorption, and partitioning. Chemical activity can be expressed as freely dissolved concentrations $\left(C_{\text {free }}\right)$ and be measured with nondepletive equilibrium-sampling methods. ${ }^{29}$ The technical challenge of measuring chemical activity and $C_{\text {free }}$ of PAHs for small particles with high $K_{\mathrm{D}}$ is to avoid artifacts related to particle adsorption to the polymer surface that can lead to overestimations of $C_{\text {free }}{ }^{30}$ (2) The accessible quantity is conceptually directly related to readily desorbing fractions and bioaccessibility. ${ }^{29}$ It describes the mass of contaminants that can be desorbed and can be measured with various mild extraction methods and depletive sampling techniques. ${ }^{31}$ The scientific challenge here is that there is no clear and welldefined distinction between accessible and nonaccessible or between desorbing and desorption resistant fractions; instead, they will always need to be operationally defined. The technical challenge of measuring bioaccessible PAHs in biochars is again related to the very high $K_{\mathrm{D}}$ values, which make it difficult to maintain a concentration gradient for desorption during the entire bioaccessibility extraction. ${ }^{32,33}$ Overcoming this problem was the basis for a new generation of (bio)accessibility extraction methods that combine a conducting media (e.g., cyclodextrin solution or simulated digestive fluid) with a sorptive sink (e.g., silicone or activated carbon). ${ }^{25,33-35}$ Recent research has shown that the inclusion of a sorption sink can lead to measurements of higher and more adequately accessible quantities. ${ }^{32,33,35}$ Although these new methods are fit for the purpose for matrices with rather high $K_{\mathrm{D}}$ values (e.g., $10^{4}-10^{6}$ $\mathrm{L} / \mathrm{kg}$ ), it remains a true challenge to provide sufficient sink capacity for samples with extreme $K_{\mathrm{D}}$ values (e.g., $>10^{6} \mathrm{~L} / \mathrm{kg}$ ).

The initial aim of this study was to find a practical yet analytically sound approach for determining the environmental exposure of PAH originating from biochars. The first phase of the study proved how difficult it can be to determine the exposure originating from high $K_{\mathrm{D}}$ matrices on the basis of the use of one single method and parameter. The aims of the study were then extended to (1) explore the applicability domain of current methods to challenging matrixes with very high $K_{\mathrm{D}}$ values, (2) make an initial assessment of PAH exposure for two selected biochars on the basis of relevant observations and measurements from all tested methods, and (3) select the best analytical strategy for determining the $\mathrm{PAH}$ exposure originating from biochar. The technical hypothesis of the work was that the capacity of the extraction system is critical when trying to determine bioaccessibilty parameters for high
$K_{\mathrm{D}}$ samples. The scientific hypothesis of the study was that biochars, and even those with relatively high PAH contents, will give rise to only limited exposure and possibly even act as a sink for PAHs in the environment.

\section{EXPERIMENTAL SECTION}

The materials (solvents, 16 USEPA PAHs, their deuterated homologues, sorptive materials, etc.) used in this study are listed in the Supporting Information.

Biochars. A total of two biochars were chosen with relatively high $\mathrm{PAH}$ contents of $63 \mathrm{mg} / \mathrm{kg}_{\text {dry weight (dw) }}$ and $355 \mathrm{mg} / \mathrm{kg}_{\mathrm{dw}} \sum 16$ USEPA PAHs (Table S1). Both biochars exceeded the threshold values set by the International Biochar Initiative (IBI) of $6 \mathrm{mg} / \mathrm{kg}_{\mathrm{dw}}$ (EU value) and $20 \mathrm{mg} / \mathrm{kg}_{\mathrm{dw}}$ (Australian value), as well as that set by the European Biochar Certificate (EBC) of $12 \mathrm{mg} / \mathrm{kg}_{\mathrm{dw}}{ }^{36,37}$ The biochars were produced from Miscanthus (elephant grass) and sieved coniferous wood residues, and additional details about these chars can be found in Hilber et al. ${ }^{38}$ Before further analysis, the biochars were dried at $40{ }^{\circ} \mathrm{C}$ overnight (losses of PAHs at this temperature were tested and found to be negligible ${ }^{39}$ ), ground to $\leq 0.75 \mathrm{~mm}$, and mixed thoroughly with a Turbula shakermixer Bachofen AG (Muttenz, Switzerland). ${ }^{38}$ The prepared biochar samples were stored in a dry and dark place with constant temperature of $21 \pm 2{ }^{\circ} \mathrm{C}$ prior to use.

Exhaustive Extraction to Determine Total Concentrations. Total concentrations of the $\sum 16$ USEPA PAHs were determined according to Hilber et al. ${ }^{38}$ Briefly, the biochars were extracted for $36 \mathrm{~h}$ with toluene by Soxhlet. Deuterated recovery standards were spiked onto the biochars immediately before the Soxhlet extraction. Following extraction, the solvent was concentrated to $1 \mathrm{~mL}$ with a Syncore Analyst system from Büchi (Flawil, Switzerland), and $\mathrm{PAH}$ concentrations were measured by gas chromatograph-mass spectroscopy (GCMS). Quantification was carried out using an internal standard method and calibration standards containing six different amounts of analytes $(10-2500 \mathrm{ng} / \mathrm{mL})$. The concentrations were not corrected for recovery.

Desorption of PAHs Determined with Tenax. Tenax (specification in the Supporting Information) provides a large surface area and high sorption capacity for PAHs, which is ideal for efficient adsorption of hydrophobic organic chemicals in desorption experiments. ${ }^{40,41}$ However, the critical step in the Tenax desorption experiments is the physical separation of Tenax particles from the matrix. ${ }^{40,42}$ Single-step Tenax extractions with $0.1 \mathrm{~g}$ of biochar, $0.6 \mathrm{~g}$ of Tenax, and $70 \mathrm{~mL}$ of water were performed for $6 \mathrm{~h}$ according to Cornelissen et al. $^{43}$ and Hilber et al. ${ }^{44}$

After the Tenax-biochar suspensions were shaken for $6 \mathrm{~h}$, the beads could not be separated from the biochar particles (Figure S1). In previous experiments, Tenax could be separated from the sediment and soil matrix using a separation funnel. ${ }^{40,44}$ However, this was not successful with the biochar because it adhered to the glass wall of the separation funnel as well as to the Tenax beads themselves. It was thus concluded that Tenax extractions could lead to an overestimation of the readily desorbing PAH fractions if biochar adheres to Tenax beads before they are solvent-extracted. No further Tenax extractions were conducted, and results are not presented.

Desorption of PAHs Determined by Cyclodextrin Extraction. Bioaccessibility extractions with hydroxylpropyl$\beta$-cyclodextrin (HPCD, Supporting Information) solutions 45,46 is a practical method that is increasingly used for bioaccessi- 
bility measurements of PAHs in soils. In this method, the solid matrix is suspended in an aqueous solution of HPCD, the matrix is then removed, and PAH concentrations in the HPCD solution are measured. The role of the HPCD is to increase the capacity of the receiving solution for PAHs but without extracting PAHs directly from the matrix. However, a recent study showed that HPCD solutions have insufficient capacity for the bioaccessibility extractions of soot materials that have high $\mathrm{PAH}$ concentrations and high $K_{\mathrm{D}}$ values. ${ }^{33}$ Partition coefficients for biochar are generally in a similar order of magnitude as for soot ${ }^{47}$ when $K_{\mathrm{D}}$ values determined at the same aqueous $\mathrm{PAH}$ concentration range are compared. It was therefore expected that HPCD solutions would also have insufficient capacity for bioaccessibility extractions of biochar, which is in line with a study by Rhodes et al. ${ }^{48}$ Simple partitioning calculations were carried out prior to experimental work to assess whether the HPCD solutions would have sufficient sink capacity with regards to the two biochars, and then the insufficient capacity was experimentally confirmed by the results of the sorptive bioaccessibility extractions (SBE; see below). Consequently, no HPCD extractions were conducted in the present study.

Desorption of PAHs determined by Sorptive Bioaccessibility Extractions. To increase the extraction capacity of the HPCD solution method, we included a sorptive sink in the HPCD solution. ${ }^{33}$ A flexible silicone rod (for specification, see the Supporting Information) was used as the absorption sink. ${ }^{33}$ A total of 3 meters of cleaned (for procedure, see the Supporting Information) silicone rod $(24 \mathrm{~g})$ were placed in a $100 \mathrm{~mL}$ glass bottle type Schott Duran (Mainz, Germany) with Teflon (PTFE)-lined screw caps, $0.1 \mathrm{~g}$ of the biochar Miscanthus was added, and $50 \mathrm{~mL}$ of a HPCD solution $(75$ $\mathrm{g}_{\mathrm{HPCD}} / \mathrm{L}_{\text {Milli-Q-water }}$ ) was added to enhance the mass-transfer of PAHs from the biochar to the silicone rod. This means that the desorption conditions were largely the same as in the traditional HPCD extractions, whereas the sink capacity was markedly increased. The bottles were wrapped in aluminum foil and shaken on a horizontal, orbital shaker (SM 25, Haska AG (Bern, Switzerland)) at $175 \mathrm{rpm}$ and at room temperature for 3 h, 9 h, 24 h, 3 days, 9 days, and 30 days (duplicates). At these times, the silicone rods were removed from the bottles, thoroughly rinsed with Milli-Q-water, and then cleaned and dried by wiping with a lint-free tissue. The silicone rods were extracted twice with $100 \mathrm{~mL}$ of acetone $(>7 \mathrm{~h}$ and then overnight). The two extracts were combined and concentrated to $1 \mathrm{~mL}$ and injected into the GC-MS for PAH analysis (see above). Deuterated standards were used in different ways to fully understand the approach. When used as recovery standards, they were added to the acetone before the silicone rods were extracted. In addition, deuterated standards were spiked into the HPCD solution at the beginning $(t=0)$ of the desorption experiment to check the efficiency of the method for transferring initially accessible PAH molecules to the silicone rod. This served also as a quality control to check whether the infinite sink conditions of the SBE method were fulfilled for these high $K_{\mathrm{D}}$ biochars. Finally, the SBE method was modified by varying the mass ratio from 240 to $9600 \mathrm{~g}$ silicone/g biochar (Table S2) to investigate the importance of the sink capacity for the final results and to extend the applicability of the SBE method toward samples with extremely high $K_{\mathrm{D}}$ values.

Desorption-Resistant PAHs Determined with Contaminant Traps. A "contaminant trap" is a simple tool for the isolation and quantification of the desorption-resistant $\mathrm{PAH}$ fraction. ${ }^{34}$ A sorbent sink is used to continuously trap the desorbed PAH molecules, eventually leaving only the desorption resistant PAHs behind in the matrix. ${ }^{34}$ The advantages of this method compared to the ones described above are the very high sink capacity that is achieved compared to HPCD extractions and SBE, and the much better phase separation that is achieved compared to the Tenax method. The disadvantage of the method is that it does not yield direct measurements of the readily desorbing fraction (i.e., bioaccessibility), whereas it can provide solid measurements of the desorption resistant PAHs that remain in the sample matrix after desorption. The method and materials used were according to Mayer et al. ${ }^{34}$ The sink in the contaminant trap glass jars is a silicone-activated carbon (AC) layer (for description, see the Supporting Information). Suspensions of $20 \mathrm{~mL}$ HPCD-solution $\left(140 \mathrm{~g}_{\mathrm{HPCD}} / \mathrm{L}_{\text {Milli-Q-water }}\right)$ and biochar $(0.1 \mathrm{~g})$ were incubated in the contaminant traps. Suspensions of biochar were placed in contact with the traps for 7, 30, and 90 days. Additionally, the suspension of the 30 day desorption batch was poured into a fresh trap container and desorption allowed to continue for a further 30 days. The glass containers were placed in the dark at a constant temperature $\left(19 \pm 1{ }^{\circ} \mathrm{C}\right)$ and were not shaken. In addition, some traps with Miscanthus biochar were shaken gently for 7 days at $50 \mathrm{rpm}$ to optimize the $\mathrm{PAH}$ mass transfer from biochar to trap surface. After the time points described above, desorption-resistant native PAHs remaining in the biochars were quantified using an exhaustive $36 \mathrm{~h}$ Soxhlet extraction. Briefly, the biochar suspensions were filtered using a $0.45 \mu \mathrm{m}$ membrane filter Millipore (Carrigtwohill, Ireland). The biochars were then rinsed with at least $0.5 \mathrm{~L}$ Milli-Q water to wash out the HPCD. The loss of biochar mass by filtration was estimated to be less than $10 \%$. The wet biochars and respective filters were dried in an oven at $40{ }^{\circ} \mathrm{C}$ for 1 day. Subsequently, the filter and biochar were subjected to Soxhlet extraction and the solvent blown down and then injected into GC-MS according to the method described in Hilber et al. ${ }^{38}$ Trap experiments were carried out in duplicate. Glass containers without sink, but with the same biochar mass and HPCD volume, were incubated in parallel. They served as controls (referred throughout this paper as "- trap") for comparison of the + trap treatments.

Freely dissolved PAH Concentrations Determined with Equilibrium Sampling. Equilibrium sampling with polyoxymethylene (POM) was applied to determine the $C_{\text {free }}$ of the native PAHs in the biochars. ${ }^{15}$ The experimental set up of the biochars in suspension with POM and water is described in the Supporting Information. The POM water partitioning coefficients $\left(K_{\mathrm{POM}}\right)$ of the PAHs were taken from Hawthorne et al. ${ }^{49}$ A total of ten blanks with only POM strips were treated the same way as the biochar samples to determine the concentration of a laboratory blank. Furthermore, the limits of detection (LoD) of six environmentally relevant PAHs (NAP, PHE, FLT, PYR, BkF, and BAP) were defined as the average of three times the noise multiplied by the lowest concentration $(10 \mathrm{ng} / \mathrm{mL}$, high concentrations tend to overestimate the signal) divided by the respective signal. The concentrations of the LoD were compiled in $\mathrm{ng} / \mathrm{mL}_{\text {solvent }}$ and as $C_{\text {free }}$ in $\mathrm{ng} / \mathrm{L}$ together with the $C_{\text {free }}$ values of biochars, the ones reported by Lang et al. in the Baltic Sea, ${ }^{50}$ and the freely dissolved LoD of Hawthorne et al. ${ }^{49}$ in Table S3. Finally, the solid-to-water distribution coefficients $\left(K_{\mathrm{D}}\right)$ were determined as the ratio of measured total concentrations and freely dissolved concentrations. 
Data Evaluation. For the SBE experiment, the mass transfer of NAP, PHE, PYR, and BaP from biochar to the silicone rod were plotted as a function of incubation time $(3 \mathrm{~h}$ to 9 days). The results were then analyzed with a one-factor analysis of variance (anova) carried out with $\mathrm{R}$ software (version 2.15.2). When time had a significant influence on the fraction of each $\mathrm{PAH}$, a pairwise, two-sided $t$ test according to Bonferroni was applied for the comparison of the individual PAHs and the different time points. The same procedure was carried out for the recoveries of the individual deuterated PAHs spiked at $t=0$. To test the overall influence of the glass container (+ trap and - trap) and the time on the $\sum 16$ USEPA PAHs in the biochars exposed to the contaminant traps, we carried out a two-factor anova. When time or the container had a significant influence, a pairwise, two-sided $t$ test according to Bonferroni was applied to compare the $\sum 16$ USEPA PAHs for each time point and for the container. The same procedure as above was repeated for the individual PAHs (NAP, PHE, PYR, $\mathrm{BkF}$, and $\mathrm{BaP})$. Comparisons were defined as significant when $p$ values were $\leq 0.05$.

\section{RESULTS AND DISCUSSION}

Sorptive Bioaccessibility Extractions. The fractions of native PAHs that were transferred from the biochar to the silicone rod were generally below $2 \%$ (Figure 1), which

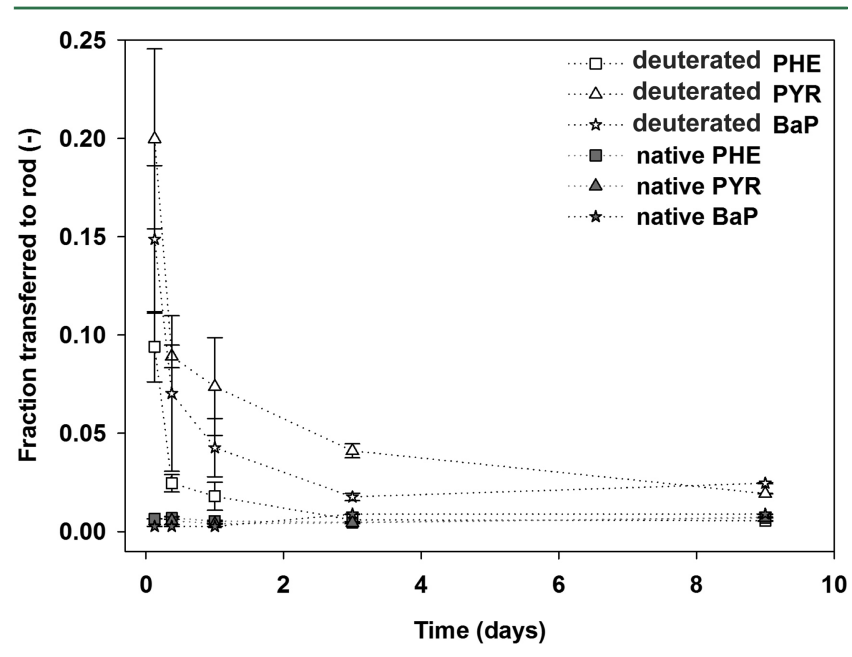

Figure 1. Sorptive bioaccessibility extraction: transfer of native PAHs and deuterated PAHs to the silicone rod as a function of time. Native PAHs were initially sorbed to the Miscanthus biochar, whereas deuterated standards were added as solvent spike. Error bars indicate standard errors of duplicates.

indicates a very low bioaccessibility. However, the picture was similar for the deuterated PAHs that were spiked at $t=0$ of the incubations (Figure 1, open symbols). Even though the silicone mass exceeded the biochar mass by 240 times, the majority of the spiked deuterated PAHs were lost to the biochar matrix over the course of the incubation, and only a small fraction was recovered on the silicone rods. This has two very important implications: (1) The sink capacity of the silicone rod was insufficient relative to the very high capacity of the biochar samples, and the SBE measurements were thus deemed invalid. The deuterated PAHs were added as solvent spike and can thus be considered initially to be in a $100 \%$ "bioaccessible" form, but their recovery by the silicone rod was generally below $20 \%$. This means that even though the SBE method had a significantly increased sink capacity relative to extractions with only $\mathrm{HPCD},{ }^{33}$ this increased sink capacity was not sufficient for the biochars. To address this, we increased the mass ratio between sink and sample up to $9600 \mathrm{~g}_{\text {silicone }} / \mathrm{g}_{\text {biochar }}$ (Table S2). These conditions provided a sufficient sink capacity for the PAHs, but the low biochar and the high silicone mass made the handling very difficult and the results prone to artifacts. These observations suggest that it is very difficult, if at all possible, to provide sufficient sink capacity for the bioaccessibility extraction of PAHs from biochars with high partition coefficients. (2) The biochar acted as a very effective sorption sink even in the presence of a much larger mass of silicone. This is the first indication that biochars, despite having significant PAH content, should be looked at as sinks rather than sources of PAHs.

Desorption-Resistant PAHs Determined with Contaminant Traps. Biochar samples of $0.1 \mathrm{~g}$ were subjected to + traps with $5 \mathrm{~g}$ of $\mathrm{AC}$ embedded in a silicone matrix, which according to calculations should have provided sufficient sink capacity. Figure 2 shows the + trap measurements against the trap measurements for some PAHs for the Miscanthus biochar (Figure 2A) and sieved coniferous wood residues biochar (Figure 2B). The incubation of biochar in the + trap up to 90 days had only a very small effect on the remaining PAH content. Both biochars showed a high desorption-resistant PAH fraction, demonstrated by the fact that the solid linear regression lines were almost congruent with the dashed 1:1 line, with slopes close to 1 (0.93 for Miscanthus biochar and 0.88 for sieved coniferous wood residues biochar). Indeed, there was no statistically significant difference between + trap and - trap for both Miscanthus and sieved coniferous wood residues biochars. Even 30 days of trapping and a second exposure for another 30 days to a fresh + trap did not decrease the desorption-resistant PAHs in either biochar. Exposure time had no significant influence for both biochars and was therefore not shown in Figure 2.

The PAH content in the sieved coniferous wood residues biochar was statistically significantly higher after 90 days incubation in the - traps and + traps than after 7, 30, and 60 days. Possibly, the wetting of biochar may have improved the PAH mass transfer during the Soxhlet extraction due to the removal of hydrophilic coatings, which may have hindered the contact with toluene during the extraction. ${ }^{16}$ Similar effects were observed by Hale et al., ${ }^{15}$ who reported that aging for one year in aqueous solutions increased the concentrations of PAHs in comparison to that of none-aged biochars, probably because hydrophilic or water-soluble constituents of biochar leached out, thereby leading to a mass loss of biochar in that case.

In addition to nonshaken systems, some traps with Miscanthus were shaken gently for 7 days at $50 \mathrm{rpm}$ to attempt to optimize the contact area of the biochar in suspension and the trap surface. The $\sum 16$ USEPA PAHs was $59.7 \pm 6.6 \mathrm{mg}$ / $\mathrm{kg}_{\mathrm{dw}}$ (mean \pm standard deviation, $n=3$ ) in the + trap shaken and $69.9 \pm 2.8 \mathrm{mg} / \mathrm{kg}_{\mathrm{dw}}$ in the $+\operatorname{trap}(n=3)$ that was not shaken. The difference was not significant ( $p$ value of $t$ test $>0.05$ ). In summary, PAH fractions released from the biochars due to the presence of the + trap were marginal at most, as the remaining total concentrations were very similar as in the trap. This shows that PAHs were overwhelmingly desorptionresistant in these two biochars.

Equilibrium Sampling Directed at Freely Dissolved Concentrations. The freely dissolved concentrations of the $\sum 16$ USEPA PAHs of the biochar from Miscanthus and sieved 

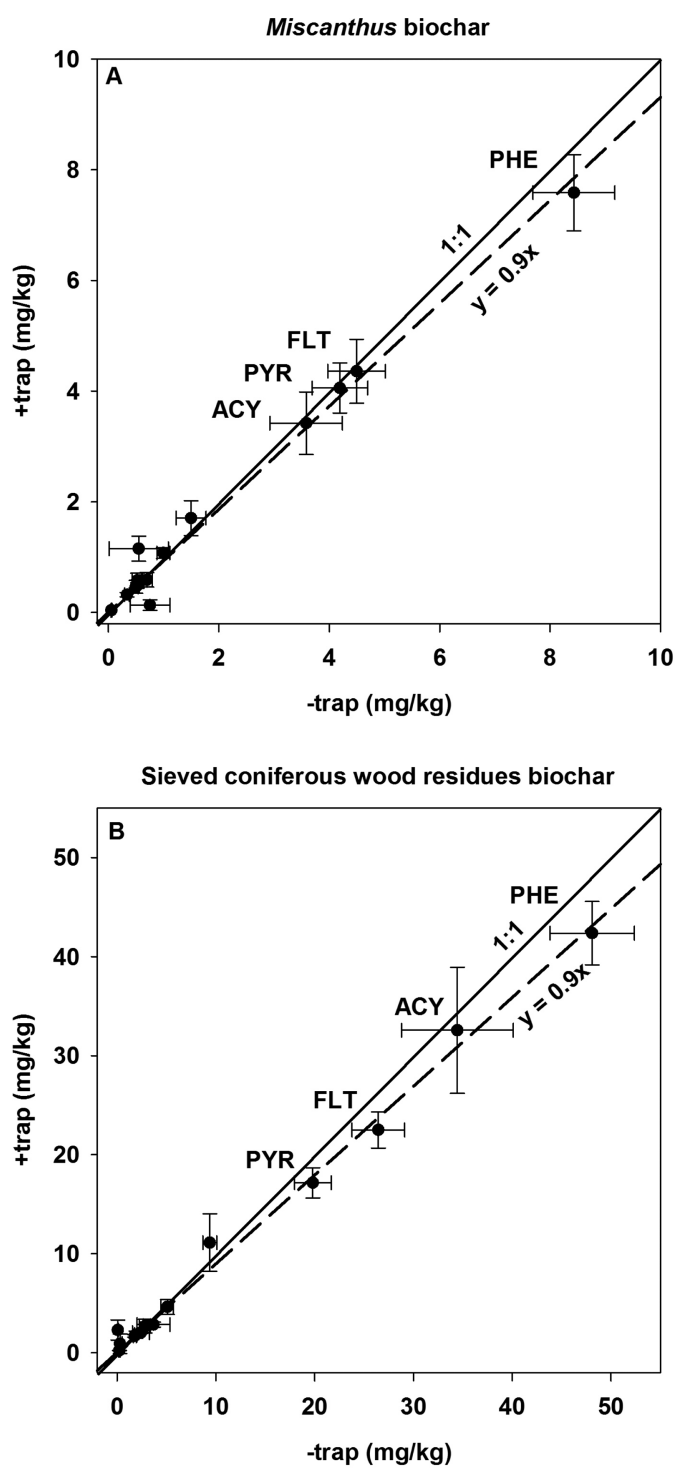

Figure 2. A total of two biochars (panels A and B) were incubated in contaminant traps (+ trap), and the remaining $\mathrm{PAH}$ content was plotted against contents in untreated biochars ( - trap) that were extracted and measured exactly at the same time. Error bars indicate the standard deviation of duplicates and fall within the symbol if not visible. Proportionality lines with slopes of 0.9 and thus near the $1: 1$ line imply a high desorption-resistant fraction near unity and, consequently, low desorbing fractions.

coniferous wood residues were $52 \pm 10$ and $71 \pm 11 \mathrm{ng} / \mathrm{L}$, respectively. PYR, PHE, and NAP in the two biochars ranged from 0.5-64.4 ng/L (Figure 3, Table S4). Generally, concentrations were low but above the laboratory blank values (Figure 3, Table S3). BaP was not detected for either biochar, and the $\mathrm{LoD}$ was around $0.002 \mathrm{ng} / \mathrm{L}$. These concentrations are factors higher than freely dissolved $\mathrm{PAH}$ concentrations determined for other slow pyrolysis biochars of $0.2-10.0 \mathrm{ng} /$ $\mathrm{L}$ but lower than what was found for gasified biochars (162 \pm $\left.71 \mathrm{ng} / \mathrm{L}^{15}\right)$. Gomez-Eyles et al. ${ }^{51}$ reported concentrations up to $100 \mathrm{ng} / \mathrm{L}$ for the $\sum 12$ USEPA PAHs assessed by $76 \mu \mathrm{m}$ thick POM in soils of up to $153 \mathrm{mg} / \mathrm{kg}_{\mathrm{dw}}$ total concentration.

Equilibrium sampling using silicone-coated glass fibers of surface sediments from 11 stations throughout the Baltic Sea revealed average $C_{\text {free }}$ of $0.07 \mathrm{ng} / \mathrm{L}$ for $\mathrm{BaP}, 0.9 \mathrm{ng} / \mathrm{L}$ for PYR, and $2.2 \mathrm{ng} / \mathrm{L}$ for $\mathrm{PHE}^{50}$ (Figure 3). Equilibrium sampling with

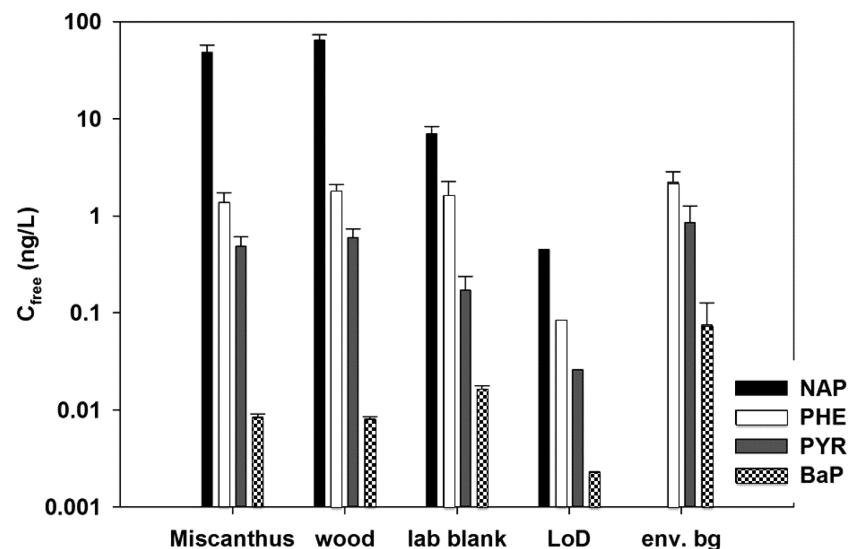

Figure 3. Freely dissolved concentrations of naphthalene (NAP), phenanthrene (PHE), pyrene (PYR), and benzo[a]pyrene $(\mathrm{BaP})$ of Miscanthus and of sieved coniferous wood residues ("wood"). Laboratory blank ("lab blank") and limit of detection (LoD) concentrations of the POM method and environmental background ("env. bg") concentrations measured in Baltic Sea sediments ${ }^{50}$ are shown for comparison. Error bars indicate standard deviations.

POM in the overlaying waters of a hot spot in the inner Oslo Harbor, Norway yielded higher concentrations for PYR (12.5 $\mathrm{ng} / \mathrm{L})$, and $\mathrm{BaP}(0.5 \mathrm{ng} / \mathrm{L})$ but lower concentrations for PHE $(0.4 \mathrm{ng} / \mathrm{L}){ }^{52}$ than in the study of Lang et al. ${ }^{50}$ (Figure 3, Table S3). Freely dissolved concentrations of PAHs in biochars are thus near or below ambient environmental levels.

The European and National (Ireland) drinking water quality standards for PAHs (single compounds not specified) have been set at $100 \mathrm{ng} / \mathrm{L} .{ }^{53}$ Typical concentrations for the sum of the PAHs (FLT, PYR, BaA, BbF, benzo[j]fluoranthene, BkF, $\mathrm{BaP}, \mathrm{DBA}, \mathrm{IPY}$, and $\mathrm{BPE}$ ) in drinking water ranged from 1 to $11000 \mathrm{ng} / \mathrm{L}$. The maximum concentration of $\mathrm{BaP}$, one of the most carcinogenic PAHs, has been set at $200 \mathrm{ng} / \mathrm{L}$. Freely dissolved PAH concentrations measured in these biochars were orders of magnitude lower than these water quality standards. $^{54,55}$

Distribution Coefficients. The distribution coefficients $\left(K_{\mathrm{D}}\right)$ were determined as the ratio of measured total and freely dissolved concentrations (Table S4). The $\log K_{\mathrm{D}}$ for the four compounds NAP, PHE, PYR, and BaP ranged between 5.7 and $8.9 \mathrm{~L} / \mathrm{kg}$ for Miscanthus biochar and between 6.5 and $9.4 \mathrm{~L} / \mathrm{kg}$ for sieved coniferous wood residues biochar. These extremely high $K_{\mathrm{D}}$ values were within the range found in the literature $\mathrm{e}^{20,56}$ when compared with measurements based on native rather than spiked PAHs at the same water concentrations. Given that adsorption to black carbon often is nonlinear, ${ }^{23,24,26} K_{D} s$ at lower aqueous concentrations in the range of a few $\mathrm{ng} / \mathrm{L}$ will typically be orders of magnitude higher compared to studies with higher spiked concentrations. ${ }^{56}$ The very high $K_{\mathrm{D}}$ values again support the fact that the biochar, despite possibly having a high PAH content, in many situations will act as a sink rather than as a source of PAHs. Furthermore, the high $K_{\mathrm{D}}$ values also explain why the large silicone mass in the SBE method had insufficient sink capacity relative to the biochar.

Technical and Conceptual Implications. The direct determination of PAH bioaccessibility did not succeed for the strongly sorbing biochar samples. Sorptive bioaccessibility extraction provided a much higher sink capacity compared to HPCD extractions without a sorbent sink. The sink capacity might have been sufficient at the highest silicone to biochar 
Table 1. Compilation of the Sorption Behavior of PAHs Originating from Biochar

\begin{tabular}{|c|c|}
\hline \multicolumn{2}{|r|}{ Observations in Support of Biochar Not Being a (Strong) Source for PAHs } \\
\hline $\begin{array}{l}\text { sorptive } \\
\text { bioaccessibility } \\
\text { extraction }\end{array}$ & very limited desorption of native PAHs in the presence of diffusive carrier and an analytical sorptive sink (Figure 1 , filled symbols). \\
\hline contaminant trap & $\begin{array}{l}\text { limited desorption of native PAHs in presence of diffusive carrier and infinite sorptive sink, even during incubations for several months (Figure } \\
\text { 2). }\end{array}$ \\
\hline $\begin{array}{l}\text { equilibrium } \\
\text { sampling }\end{array}$ & $\begin{array}{l}\text { measured freely dissolved concentrations of the lower molecular weight PAHs did not exceed environmental levels, and freely dissolved } \\
\text { concentrations of the higher molecular weight PAHs were below analytical (GC-MS) detection limits (Figure 3, Table S3). }\end{array}$ \\
\hline \multicolumn{2}{|r|}{ Observations in Support of Biochar Even Being a Sink for PAHs } \\
\hline $\begin{array}{l}\text { sorptive } \\
\text { bioaccessibility } \\
\text { extraction }\end{array}$ & $\begin{array}{l}\text { After } 9 \text { days, less than } 10 \% \text { of the deuterated internal standards were measured in the silicone rod, indicating that the vast majority of the } \\
\text { deuterated internal standards were lost to the biochar (Figure 1, empty symbols). }\end{array}$ \\
\hline equilibrium sampling & $\begin{array}{l}\text { Concentrations of some PAHs in the sampling polymer did not increase but decreased during contact with the biochar }\left(C_{\mathrm{POM}} \text {, biochar }<\right. \\
C_{\text {laboratory,Blank }} \text { ) (Figure 3, Table S3). }\end{array}$ \\
\hline equilibriun & Equilibrium sampling yielded freely dissolved concentrations of PAHs that were mostly below environmental levels (Figure 3, Table S3). \\
\hline
\end{tabular}

ratios (i.e., $9600 \mathrm{~g}_{\text {silicone }} / \mathrm{g}_{\text {biochar }}$ ); however, this was impractical and likely prone to artifacts related to biochar particles adhering to the large silicone surface. The results of the present study question the application of common bioaccessibility extraction methods to samples with extremely high $K_{\mathrm{D}}$ values. A different sorbent material or even a completely different configuration is needed to provide sufficient sink capacity relative to the extremely high capacity of the biochar sample. The results of the present study even question the suitability and meaningfulness of the bioaccessibility concept for samples with very high $K_{\mathrm{D}}$ values. What does a certain bioaccessibility estimate really mean if the matrix mainly acts as a sink rather than as a source? The contaminant traps were generally found to be suitable for quantifying the desorption resistant $\mathrm{PAH}$ content in the biochars. However, there were still some technical challenges related to this method that would require additional adjustments and improvements before its widescale adoption. Equilibrium sampling with POM was generally found to be suitable for measuring freely dissolved PAH concentrations in biochar. The use of equilibrium passive sampling is robust and cheap and provides reliable measurements. Special attention should be paid in future biochar studies to the precleaning of the equilibrium sampling polymer because freely dissolved $\mathrm{PAH}$ concentrations can, as shown in the present study, be very low despite a relatively high $\mathrm{PAH}$ content. Although the present study focuses on how to determine the PAH exposure originating from biochar, we consider many of the methodological and conceptual aspects of the study highly relevant also for other organic carbon-rich matrices with high to extremely high $K_{\mathrm{D}}$ values. Such matrices include soot, charcoal, activated carbon, and also certain types of historically contaminated soils.

Environmental Implications. Even though the total PAH concentrations in the two biochars exceeded the threshold values of the IBI and EBC, several observations suggest that these biochars only gave rise to limited $\mathrm{PAH}$ exposure and most often would act as sorption sink rather than as a source for PAHs (Table 1). It remains very difficult to directly quantify the PAH fraction that can be released from the biochars (bioaccessibility). However, the desorption experiments using the contaminant traps clearly showed that most of the biochar bound PAHs were desorption-resistant and that it was extremely difficult to mobilize the PAHs from the biochar matrix. Equilibrium sampling yielded very low $C_{\text {free }}$ values, which were below or near environmental levels and again supported a very limited PAH release. The general characteristics of the two biochars is thus that they have a rather high $\mathrm{PAH}$ content but that they, due to extremely high $K_{\mathrm{D}}$ values, often will act as a sink rather than as a source of PAHs. This gives the tested biochars many commonalities with soot particles, charcoal, and also some historically polluted soils, $^{23,24,26}$ and research on a broader range of biochars is now required to determine to which degree the obtained findings can be generalized to the full range of biochars, which can be produced from all kinds of biomass and also using different pyrolysis technologies and conditions. Finally, biochars will often be mixed into other matrices and will then often be a minor constituent in terms of mass but a significant or dominant constituent in terms of PAH sorption. It is therefore important to also study the exposure and bioavailability of PAHs when biochars are amended to soils and other matrices. ${ }^{57}$ Even in such studies on biochar-amended soils, it remains crucial to provide sufficient sink capacity during bioaccessibility extractions to avoid the underestimation of exposure and bioavailability. ${ }^{32}$

\section{ASSOCIATED CONTENT}

\section{S Supporting Information}

The Supporting Information is available free of charge on the ACS Publications website at DOI: 10.1021/acs.est.5b05603.

Additional experimental details. Tables showing properties of the biochars and total concentrations of the 16 US EPA PAHs; range of mass ratios between sink (silicone rod) and matrix (biochar); freely dissolved concentrations of six environmentally important PAHs of the two biochars, of the Baltic Sea serving as environmental background, of the laboratory blanks (passive sampler without biochar), and of the GC-MS limits of detection (LoD) in $\mathrm{ng} / \mathrm{L}$; and the freely dissolved concentrations $\left(C_{\text {free }}\right)$ of the Miscanthus and sieved coniferous wood residues biochars and the distribution coefficients $(K i, D)$ calculated from the $C_{\text {free }}$ and the total PAH concentration. A figure showing a Tenax and biochar mixture. (PDF)

\section{AUTHOR INFORMATION}

\section{Corresponding Author}

*Phone: +45 452515 69; e-mail: philm@env.dtu.dk.

\section{Funding}

This work was supported by a grant from the Polish-Swiss Research Programme through the Swiss Contribution to the enlarged European Union. P.M. acknowledges the financial support through the MACATA project (EFRE \& Lower Austria). 


\section{Notes}

The authors declare no competing financial interest.

\section{ACKNOWLEDGMENTS}

We thank Kevser Güder and Franziska Blum for their lab work, Hans-Peter Schmidt for donation of the biochars, and Gesine Witt for providing environmental background measurements from the Baltic Sea.

\section{REFERENCES}

(1) Verheijen, F.; Jeffery, S.; Bastos, A. C.; Van der Velde, L. E.; Diafas, I. Biochar application to soils: A critical scientific review of effects on soil properites, processes and functions; Office for the Official Publications of the European Communities: Luxembourg, 2009; p 149.

(2) Cowie, A.; Woolf, D.; Gaunt, J.; Brandão, M.; Anaya de la Rosa, R.; Cowie, A. Biochar, carbon accounting and climate change. In Biochar for Environmental Management: Science, Technology and Implementation; Lehmann, J., Joseph, S., Ed.; earthscan: London, UK, 2015; pp 763-794.

(3) Whitman, T.; Singh, B. P.; Zimmerman, A. R.; Lehmann, J.; Joseph, S. Priming effects in biochar-amended soils: Implications of biochar-soil organic matter interactions for carbon storage. In Biochar for Environmental Management: Science, Technology and Implementation; Lehmann, J., Joseph, S., Ed.; earthscan: London, UK, 2015; pp 455488.

(4) DeLuca, T. H.; MacKenzie, M. D.; Gundale, M. J.; Jones, D. L. Biochar effects on soil nutrient transformations. In Biochar for Environmental Management: Science, Technology and Implementation; Lehmann, J., Joseph, S., Ed.; earthscan: London, UK, 2015; pp 421454.

(5) Jeffery, S.; Abalos, D.; Spokas, K. A.; Verheijen, F. G. Biochar effects on crop yield. In Biochar for Environmental Management: Science, Technology and Implementation; Lehmann, J., Joseph, S., Ed.; earthscan: London, UK, 2015; pp 301-326.

(6) Kammann, C.; Graber, E. R. Biochar effects on plant ecophysiology. In Biochar for Environmental Management: Science, Technology and Implementation; Lehmann, J., Joseph, S., Ed.; earthscan: London, UK, 2015; pp 391-420.

(7) Lehmann, J.; Abiven, S.; Kleber, M.; Pan, G.; Singh, B. P.; Sohi, S. P.; Zimmerman, A. R.; Lehmann, J.; Joseph, S. Persistence of biochar in soil. In Biochar for Environmental Management: Science, Technology and Implementation; Lehmann, J., Joseph, S., Ed.; earthscan: London, UK, 2015; pp 235-282.

(8) Rumpel, C.; Leifeld, J.; Santin, C.; Doerr, S. Movement of biochar in the environment. In Biochar for Environmental Management: Science, Technology and Implementation; Lehmann, J., Joseph, S., Ed.; earthscan: London, UK, 2015; pp 283-300.

(9) Thies, J. E.; Rillig, M. C.; Graber, E. R. Biochar effects on the abundance, activity and diversity of the soil biota. In Biochar for Environmental Management: Science, Technology and Implementation; Lehmann, J., Joseph, S., Ed.; earthscan: London, UK, 2015; pp 327390.

(10) Laird, D.; Rogovska, N. Biochar effects on nutrient leaching. In Biochar for Environmental Management: Science, Technology and Implementation; Lehmann, J., Joseph, S., Ed.; earthscan: London, UK, 2015; pp 521-542.

(11) Masiello, C.; Dugan, B.; Brewer, C.; Spokas, K.; Novak, J.; Liu, Z.; Sorrenti, G. Biochar effects on soil hydrology. In Biochar for Environmental Management: Science, Technology and Implementation; Lehmann, J., Joseph, S., Ed.; earthscan: London, UK, 2015; pp 543562.

(12) Steiner, C.; Sánchez-Monedero, M.; Kammann, C. Biochar as an additive to compost and growing media. In Biochar for Environmental Management: Science, Technology and Implementation; Lehmann, J., Joseph, S., Ed.; earthscan: London, UK, 2015; pp 717-736.

(13) Chu, G. M.; Jung, C. K.; Kim, H. Y.; Ha, J. H.; Kim, J. H.; Jung, M. S.; Lee, S. J.; Song, Y.; Ibrahim, R. I. H.; Cho, J. H.; Lee, S. S.; Song,
Y. M. Effects of bamboo charcoal and bamboo vinegar as antibiotic alternatives on growth performance, immune responses and fecal microflora population in fattening pigs. Anim. Sci. J. 2013, 84 (2), 113-120.

(14) Chen, Y.-X.; Huang, X.-D.; Han, Z.-Y.; Huang, X.; Hu, B.; Shi, D.-Z.; Wu, W.-X. Effects of bamboo charcoal and bamboo vinegar on nitrogen conservation and heavy metals immobility during pig manure composting. Chemosphere 2010, 78 (9), 1177-1181.

(15) Hale, S. E.; Lehmann, J.; Rutherford, D.; Zimmerman, A. R.; Bachmann, R. T.; Shitumbanuma, V.; O’Toole, A.; Sundqvist, K. L.; Arp, H. P. H.; Cornelissen, G. Quantifying the total and bioavailable polycyclic aromatic hydrocarbons and dioxins in biochars. Environ. Sci. Technol. 2012, 46 (5), 2830-2838.

(16) Bucheli, T. D.; Hilber, I.; Schmidt, H. Polycyclic aromatic hydrocarbons and polychlorinated aromatic compounds in biochar. In Biochar for Environmental Management: Science, Technology and Implementation; Lehmann, J., Joseph, S., Ed.; earthscan: London, UK, 2015; pp 595-624.

(17) Keiluweit, M.; Kleber, M.; Sparrow, M. A.; Simoneit, B. R.; Prahl, F. G. Solvent-extractable polycyclic aromatic hydrocarbons in biochar: influence of pyrolysis temperature and feedstock. Environ. Sci. Technol. 2012, 46 (17), 9333-9341.

(18) Kloss, S.; Zehetner, F.; Dellantonio, A.; Hamid, R.; Ottner, F.; Liedtke, V.; Schwanninger, M.; Gerzabek, M. H.; Soja, G. Characterization of slow pyrolysis biochars: Effects of feedstocks and pyrolysis temperature on biochar properties. J. Environ. Qual. 2012, 41 (4), 990-1000.

(19) Schimmelpfennig, S.; Glaser, B. One step forward toward characterization: Some important material properties to distinguish biochars. J. Environ. Qual. 2012, 41 (4), 1001-1013.

(20) Hale, S. E.; Cornelissen, G.; Werner, D. Sorption and remedition of organic compounds in soils and sediments by (activated) biochar. In Biochar for Environmental Management: Science, Technology and Implementation; Lehmann, J., Joseph, S., Ed.; earthscan: London, UK, 2015; pp 625-654.

(21) Jonker, M. T. O.; Koelmans, A. A. Sorption of polycyclic aromatic hydrocarbons and polychlorinated biphenyls to soot and soot-like materials in the aqueous environment mechanistic considerations. Environ. Sci. Technol. 2002, 36 (17), 3725-3734.

(22) Cornelissen, G.; Gustafsson, O. Prediction of large variation in biota to sediment accumulation factors due to concentrationdependent black carbon adsorption of planar hydrophobic organic compounds. Environ. Toxicol. Chem. 2005, 24 (3), 495-498.

(23) Koelmans, A. A.; Jonker, M. T. O.; Cornelissen, G.; Bucheli, T. D.; Van Noort, P. C. M.; Gustafsson, Ö. Black carbon: The reverse of its dark side. Chemosphere 2006, 63 (3), 365-377.

(24) Cornelissen, G.; Gustafsson, O.; Bucheli, T. D.; Jonker, M. T. O.; Koelmans, A. A.; Van Noort, P. C. M. Extensive sorption of organic compounds to black carbon, coal, and kerogen in sediments and soils: Mechanisms and consequences for distribution, bioaccumulation, and biodegradation. Environ. Sci. Technol. 2005, 39 (18), 68816895.

(25) Gouliarmou, V.; Collins, C. D.; Christiansen, E.; Mayer, P. Sorptive physiologically based extraction of contaminated solid matrices: Incorporating silicone rod as absorption sink for hydrophobic organic contaminants. Environ. Sci. Technol. 2013, 47 (2), 941948.

(26) Reichenberg, F.; Karlson, U. G.; Gustafsson, Ö.; Long, S. M.; Pritchard, P. H.; Mayer, P. Low accessibility and chemical activity of PAHs restrict bioremediation and risk of exposure in a manufactured gas plant soil. Environ. Pollut. 2010, 158 (5), 1214-1220.

(27) Hilber, I.; Bucheli, T. D. Activated carbon amendment to remediate contaminated sediments and soils: A review. Global Nest J. 2010, 12 (3), 305-307.

(28) Kupryianchyk, D.; Rakowska, M. I.; Grotenhuis, J. T. C.; Koelmans, A. A. In situ sorption of hydrophobic organic compounds to sediment amended with activated carbon. Environ. Pollut. 2012, 161, $23-29$. 
(29) Reichenberg, F.; Mayer, P. Two complementary sides of bioavailability: Accessibility and chemical activity of organic contaminants in sediments and soils. Environ. Toxicol. Chem. 2006, 25 (5), $1239-1245$.

(30) Jonker, M. T. O.; Koelmans, A. A. Polyoxymethylene solid phase extraction as a partitioning method for hydrophobic organic chemicals in sediment and soot. Environ. Sci. Technol. 2001, 35 (18), $3742-3748$.

(31) Cui, X.; Mayer, P.; Gan, J. Methods to assess bioavailability of hydrophobic organic contaminants: Principles, operations, and limitations. Environ. Pollut. 2013, 172, 223-234.

(32) Collins, C. D.; Mosquera-Vazquez, M.; Gomez-Eyles, J. L.; Mayer, P.; Gouliarmou, V.; Blum, F. Is there sufficient 'sink' in current bioaccessibility determinations of organic pollutants in soils? Environ. Pollut. 2013, 181, 128-132.

(33) Gouliarmou, V.; Mayer, P. Sorptive bioaccessibility extraction (SBE) of soils: Combining a mobilization medium with an absorption sink. Environ. Sci. Technol. 2012, 46 (19), 10682-10689.

(34) Mayer, P.; Olsen, J. L.; Gouliarmou, V.; Hasinger, M.; Kendler, R.; Loibner, A. P. A contaminant trap as a tool for isolating and measuring the desorption resistant fraction of soil pollutants. Environ. Sci. Technol. 2011, 45 (7), 2932-2937.

(35) Zhang, Y.; Pignatello, J. J.; Tao, S.; Xing, B. Bioacessibility of PAHs in fuel soot assessed by an in vitro digestive model: Effect of including an absorptive sink. Environ. Sci. Technol. 2015, 49 (6), 39053912.

(36) IBI, International Biochar Initiative http://www.biocharinternational.org/sites/default/files/IBI_Biochar_Standards_V1.1.pdf (accessed April 26, 2013).

(37) EBC, European Biochar Certificate, http://www.europeanbiochar.org/biochar/media/doc/ebc-guidelines.pdf (accessed August 2015), version 6.1 of June 19th, 2015.

(38) Hilber, I.; Blum, F.; Leifeld, J.; Schmidt, H. P.; Bucheli, T. D. Quantitative determination of PAHs in biochar: A prerequisite to ensure its quality and safe application. J. Agric. Food Chem. 2012, 60 (12), 3042-3050

(39) Desaules, A.; Ammann, S.; Blum, F.; Brandli, R. C.; Bucheli, T. D.; Keller, A. PAH and PCB in soils of Switzerland - status and critical review. J. Environ. Monit. 2008, 10 (11), 1265-1277.

(40) Cornelissen, G.; vanNoort, P. C. M.; Govers, H. A. J. Desorption kinetics of chlorobenzenes, polycyclic aromatic hydrocarbons, and polychlorinated biphenyls: Sediment extraction with Tenax ${ }^{\circledR}$ and effects of contact time and solute hydrophobicity. Environ. Toxicol. Chem. 1997, 16 (7), 1351-1357.

(41) Pignatello, J. J. Slowly Reversible Sorption of Aliphatic Halocarbons in Soils 0.1. Formation of Residual Fractions. Environ. Toxicol. Chem. 1990, 9 (9), 1107-1115.

(42) Cuypers, C.; Pancras, T.; Grotenhuis, T.; Rulkens, W. The estimation of PAH bioavailability in contaminated sediments using hydroxypropyl- $\beta$-cyclodextrin and Triton X-100 extraction techniques. Chemosphere 2002, 46 (8), 1235-1245.

(43) Cornelissen, G.; Rigterink, H.; ten Hulscher, D. E. M.; Vrind, B. A.; van Noort, P. C. M. A simple Tenax ${ }^{\circledR}$ extraction method to determine the availability of sediment-sorbed organic compounds. Environ. Toxicol. Chem. 2001, 20 (4), 706-711.

(44) Hilber, I.; Bucheli, T. D.; Wyss, G.; Schulin, R. Assessing the phytoavailability of dieldrin residues in charcoal-amended soil using Tenax® extraction. J. Agric. Food Chem. 2009, 57 (10), 4293-4298.

(45) Reid, B. J.; Stokes, J. D.; Jones, K. C.; Semple, K. T. Nonexhaustive cyclodextrin-based extraction technique for the evaluation of PAH bioavailability. Environ. Sci. Technol. 2000, 34 (15), 3174-3179.

(46) Cuypers, C.; Grotenhuis, T.; Joziasse, J.; Rulkens, W. Rapid persulfate oxidation predicts PAH bioavailability in soils and sediments. Environ. Sci. Technol. 2000, 34 (10), 2057-2063.

(47) Bucheli, T. D.; Gustafsson, O. Quantification of the soot-water distribution coefficient of PAHs provides mechanistic basis for enhanced sorption observations. Environ. Sci. Technol. 2000, 34 (24), 5144-5151.
(48) Rhodes, A. H.; Riding, M. J.; McAllister, L. E.; Lee, K.; Semple, K. T. Influence of activated charcoal on desorption kinetics and biodegradation of phenanthrene in soil. Environ. Sci. Technol. 2012, 46 (22), 12445-12451.

(49) Hawthorne, S. B.; Jonker, M. T. O.; van der Heijden, S. A.; Grabanski, C. B.; Azzolina, N. A.; Miller, D. J. Measuring picogram per liter concentrations of freely dissolved parent and alkyl PAHs (PAH34), using passive sampling with polyoxymethylene. Anal. Chem. 2011, 83 (17), 6754-6761.

(50) Lang, S.-C.; Hursthouse, A.; Mayer, P.; Kötke, D.; Hand, I.; Schulz-Bull, D.; Witt, G. Equilibrium passive sampling as a tool to study polycyclic aromatic hydrocarbons in Baltic Sea sediment porewater systems. Mar. Pollut. Bull. 2015, 101 (1), 296-303.

(51) Gomez-Eyles, J. L.; Jonker, M. T. O.; Hodson, M. E.; Collins, C. D. Passive samplers provide a better prediction of PAH bioaccumulation in earthworms and plant roots than exhaustive, mild solvent, and cyclodextrin extractions. Environ. Sci. Technol. 2012, 46 (2), 962-969.

(52) Cornelissen, G.; Pettersen, A.; Broman, D.; Mayer, P.; Breedveld, G. D. Field testing of equilibrium passive samplers to determine freely dissolved native polycyclic aromatic hydrocarbon concentrations. Environ. Toxicol. Chem. 2008, 27 (3), 499-508.

(53) European and National Drinking Water Quality Standards, Northern Ireland Environment Agency: Belfast, Ireland, 2014; p 12.

(54) World Health Organization Guidelines for Drinking-Water Quality, 4th edition; World Health Organization: Geneva, Switzerland, 2011; p. 564.

(55) EPA. National Primary Drinking Water Regulations, 2009; http://water.epa.gov/drink/contaminants/upload/mcl-2.pdf (accessed Oct 13 2015), p. 6.

(56) Hale, S. E.; Arp, H. P. H.; Kupryianchyk, D.; Cornelissen, G. A synthesis of parameters related to the binding of neutral organic compounds to charcoal. Chemosphere 2016, 144, 65-74.

(57) Gomez-Eyles, J. L.; Sizmur, T.; Collins, C. D.; Hodson, M. E. Effects of biochar and the earthworm Eisenia fetida on the bioavailability of polycyclic aromatic hydrocarbons and potentially toxic elements. Environ. Pollut. 2011, 159 (2), 616-622. 